\title{
TYPE 2 DIABETES MELLITUS: A RISK FACTOR OF AGGRESSION IN ADULTS
}

\section{Riffat Sadiq $^{1 \otimes}$, Fakiha Shoukat', Aiman Ejaz', Maryam Waris', Aleena Kashif', Maria Ejaz'}

\section{ABSTRACT}

OBJECTIVE: To examine the problem of aggression (physical aggression, verbal aggression, anger and hostility) among patients with type 2 diabetes mellitus (T2DM) in comparison to normal adults.

METHODS: The present study was carried out from February to April 2019 in Faisalabad city that employed comparative research method with independent group research design. One hundred $(n=100)$ patients suffering from T2DM, and one hundred $(n=100)$ non-diabetic participants (normal adults) were recruited. Aggression Questionnaire was used to examine the aggression (physical aggression, verbal aggression, anger and hostility) among all participants. Data were analyzed with descriptive statistics, Shapiro-Wilk normality test and independent samples t-test via SPSS, Version 22.0.

RESULTS: Normality test indicated the normal distribution of data $(p=.447)$ related to aggression questionnaire. Results of independent samples t-test revealed that adults with T2DM reported more aggression $(t=3.90, d f=198, p$ $=.000)$, verbal aggression $(\mathrm{t}=2.85, \mathrm{df}=198, \mathrm{p}=.005)$, anger $(\mathrm{t}=2.92$, $\mathrm{df}=198, \mathrm{p}=.004)$ and hostility $(\mathrm{t}=4.29, \mathrm{df}=198, \mathrm{p}=.000)$ than normal adults. Both groups did not report physical aggression with significant difference $(\mathrm{t}=1.34, \mathrm{df}=198, \mathrm{p}=.180)$.

CONCLUSION: T2DM is a potent risk factor of aggression in adults. T2DM patients mostly become verbally aggressive towards others. They also respond to external environment with intense anger and hostility. Thus, management of aggressive thoughts and acts is equally essential besides coping with the disease.

KEY WORDS: Diabetes Mellitus, Type 2 (MeSH); Aggression (MeSH); Anger (MeSH); Hostility (MeSH); Aggression Questionnaire (Non-MeSH); Patients (MeSH).

THIS ARTICLE MAY BE CITED AS: Sadiq R, Shoukat F, Ejaz A, Waris M, Kashif A, Ejaz M. Type 2 diabetes mellitus: a risk factor of aggression in adults. Khyber Med Univ J 202I;13(2):103-7. https://doi.org/l0.35845/ kmuj.2021.19778.

\section{INTRODUCTION}

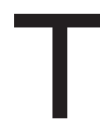

he chronic disease of diabetes mellitus, irrespective of its types, is alarming for entire world. About 422 million people became the victim of diabetes mellitus worldwide.' According to the calculation of International Diabetes Federation, the prevalence of diabetes mellitus is likely to reach around 700 million by 2045 . Exclusively in Pakistan, the estimated prevalence of diabetes in 2000 was $5,217,000$ and is expected to touch the numbers of $13,853,000$ till 2030 . $^{2}$ Consequently, in near the future, Pakistan will be standing at fourth among the list of countries adversely affected by diabetes mellitus. ${ }^{3}$ Type 2 diabetes mellitus (T2DM) is one form of diabetes associated with deficient pancreas that fails to release sufficient insulin required to maintain the level of glucose in the body. The interplay of genetic, environmental and behavioral factors is evident in developing T2DM. ${ }^{4}$

Researches have delineated the deleterious impact of diabetes on physical, psychological and social functioning of the patients. ${ }^{5}$ Diabetic patients keep struggling with psychological and emotional burden associated with disease. ${ }^{6}$ Its victims report more tiredness and dizziness and less energy in their body. ${ }^{7}$ Researches also revealed a close link of diabetes mellitus with distress, ${ }^{8}$ worry and
I Department of Applied Psychology, Government College Women University Faisalabad, Faisalabad, Pakistan. Email冈: drriffat.haider@gcwuf.edu.pk Contact \#: +92-334-5307777

Date Submitted: October 05, 2019

Date Revised: April 09, 2021

Date Accepted: April 14, 2021

anxiety, ${ }^{9}$ eating disorder, ${ }^{10}$ adjustment disorder," depression and anxiety, ${ }^{12}$ stress, ${ }^{13,14}$ and anger ${ }^{14,15}$ as well. Likewise, aggression may be added to the list of those behavioral and emotional problems diabetic patients may experience as a function of diabetes mellitus. Scientific literature elucidates aggression as a dark facet of human nature. ${ }^{16}$ It is deemed as maladaptive behavior that brings harm and obliteration to someone. ${ }^{17}$ A person may express his or her aggressive impulses in the form of physical aggression, verbal aggression, anger and hostility. ${ }^{18}$ Sometimes, this expression may become the cause of intense violence towards external world. ${ }^{19}$

Thus, reasons and causes working behind the aggressive acts need to be brought on the surface in order to prevent the self and others from dire consequences of aggression. Diabetes mellitus, specifically type 2 , is expected to be risky for people as it may propagate aggression in them. Although, previous scientific work targeted the diabetes mellitus in respect to variety of psychological problems, as mentioned above, but aggression is one kind of psychological problem that has not been exclusively focused in the connection of T2DM. Patients with diabetes mellitus are usually observed exhibiting aggression in different forms. They are found to be complaining of poor control over their aggressive tendencies. So, the role of diabetes mellitus in increasing aggressive feelings and acts need to be thoroughly examined. The present study will add the aggression in the list of already highlighted psychosocial problems the patients with T2DM experienced as the consequences of 
TABLE I: SUMMARY OF DEMOGRAPHIC CHARACTERISTICS OF ALL PARTICIPANTS ( $\mathbf{N}=\mathbf{2 0 0})$

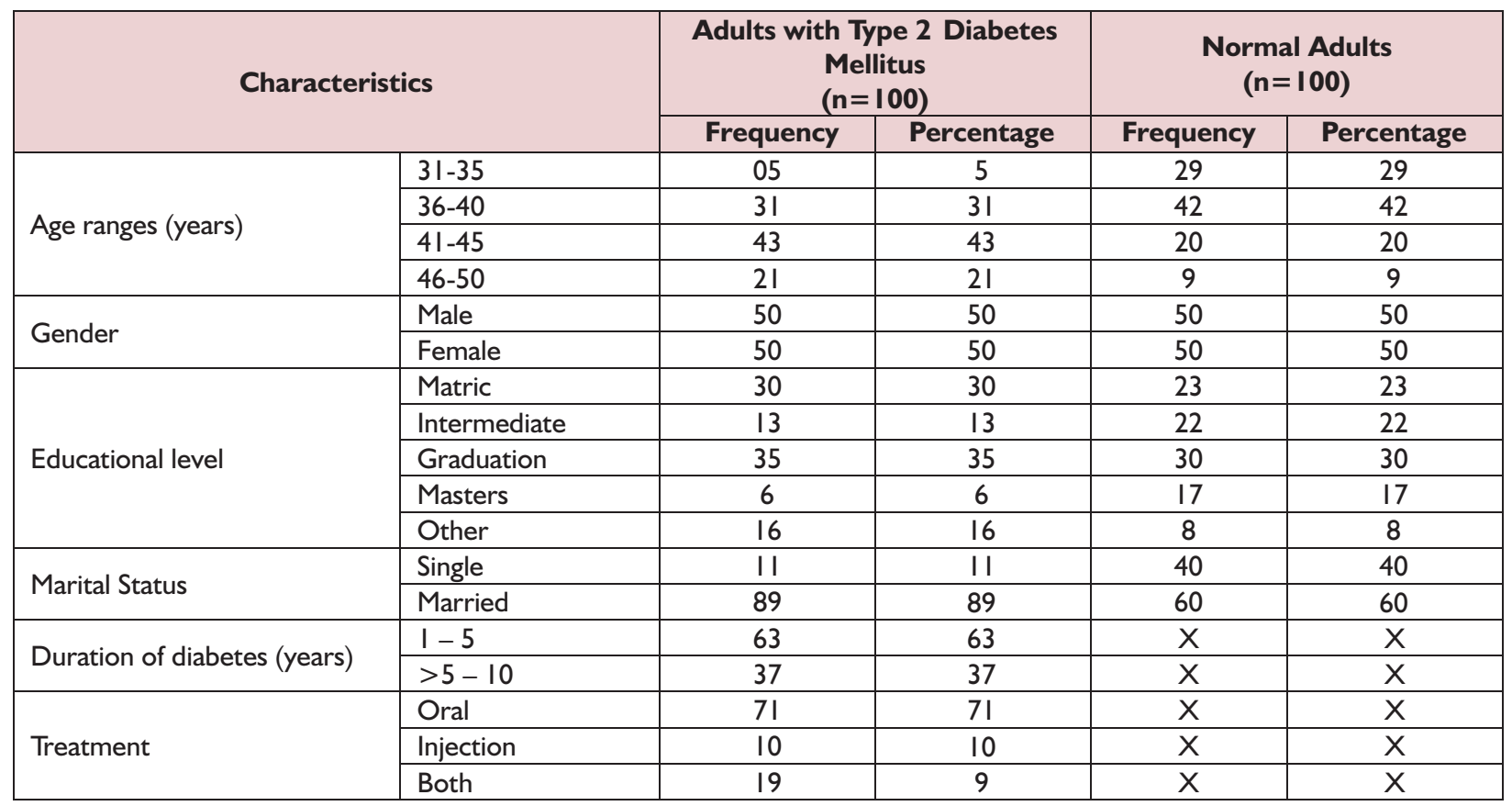

their disease. In this connection, the objective of the present study is to probe the aggression in adults with and without T2DM in comparison to each other. With present aim and objective, following hypothesis was postulated:

- Adults with T2DM will significantly report more aggression (physical aggression, verbal aggression, anger and hostility) than normal adults.

\section{METHODS}

Having approval from the Ethical Review Committee, the present study was carried out from February to April 2019 in Faisalabad city that employed comparative research method with independent group research design. A priori: compute required sample size (Mean: Differences between two independent means) through g-power calculator determined the number of $(n=176)$ as a whole and eighty eight $(n=88)$ for each group, with statistical power (0.95) and effect size (0.5) at (0.05) alpha level. But for the present study, it was decided to take two hundred participants, one hundred for each group, considering their availability. One hundred $(n=100)$ patients with T2DM were conveniently selected from private clinics and hospitals serving the Faisalabad populace. While, comparative group that comprised of one hundred $(n=100)$ normal adults were selected from general population through snowball sampling method.

The age ranges of both groups were 31 to 50 years. Equal number of male and female participants was recruited in both groups in order to avoid gender bias. Minimum duration of diabetes mellitus was one year for selected patients. Diabetic patients with other physical complications (i.e, neuropathy, kidney problem, hepatitis, cardiac issue, hypertension, etc) were not included in the study. On the other hand, normal adults were also required to ensure the absence of any kind of physical or mental health issue (i.e, hepatitis, diabetes, asthma, hypertension, disability, mental health disorder, etc). Additionally, unemployed, divorcee, widow, parents of physically/emotionally handicapped children were excluded from the present study.

Before collecting present research data, permission was taken from the administration of hospitals/doctors treating diabetic patients in their private clinics. The severity of disease and associated complications were confirmed from the doctors of every patient included in the study. Then, consent was also taken from the patients with T2DM while briefing them the research purpose, procedure and associated risk/benefit ratio. Similarly, consent was also taken from comparative groups (normal adults). When participants confirmed their willingness to take part in the study by signing the informed consent form, they were given instruments to be filled by their own self. Data was collected from every participant in individual setting (hospitals or clinics for patients; workplaces/homes for normal adults). Required personal information was taken with Personal Information Sheet designed for the present study. It included information as to age, gender educational level, marital status, duration of diabetes, and treatment taken for disease management.

Aggression was checked using 29-items Aggression Questionnaire. ${ }^{18}$ It has four subscales including physical aggression (9-items), verbal aggression (5-items), anger (7-items) and hostility (8-items). Items of all subscales are scored on 5point Likert scale [Extremely uncharacteristic of me $=I$, Somewhat uncharacteristic of me $=2$, Neither uncharacteristic nor characteristic of me $=3$, Somewhat characteristic of me $=4$, Extremely characteristic of me $=5]$. English version of Aggression Questionnaire has been documented as 
reliable scale. Its full scale reliability ranged from 0.72 to 0.80 , while reliability of subscales ranged from 0.72 to 0.85 . Reliability of Urdu version of full scale is 0.92 , whereas reliability of subscales ranged from 0.65 to $0.90 .^{20} \mathrm{At}$ the end, obtained research data through instruments were scored and statistically analyzed by computing descriptive statistics, Shapiro-Wilk normality test and independent samples t-test using SPSS Version, 22.0.

\section{RESULTS}

Concerning personal demographic information, analysis (Table I) showed the equal recruitment of male $(50 \%)$ and female (50\%) participants. Majority patients $(43 \%)$ were falling in the age range of 41 to 45 years. Graduation was noted as the minimum educational level of most of the patients (35\%), while majority (89\%) was married among them. About I to 5 years was minimum duration of diabetes of majority patients $(63 \%)$ and most of them (7I\%) were taking oral treatment for their disease. Majority of normal adults (42\%) were in the age ranges of 36 to 40 years and about $30 \%$ were having the bachelor degree (1 4 years of education). Majority of them $(60 \%)$ were also married.

Analysis done by Shapiro-Wilk normality test revealed that the obtained data on the aggression questionnaire is normally distributed (Shapiro-Wilk Statistics 0.993, $\mathrm{Df}=200 \mathrm{p}=0.447$ ).

Independent samples t-test (Table II) revealed a significant difference between two groups in respect to aggression and its domain except physical aggression. Adults with T2DM reported more aggression $(t=3.90, d f=198, p=0.000)$, verbal aggression $(t=2.85, d f=198$, $p=0.005)$, anger $(t=2.92, d f=198$, $\mathrm{p}=.004)$ and hostility $(\mathrm{t}=4.29, \mathrm{df}=198$, $\mathrm{p}=0.000)$ than normal adults. Both groups did not report physical aggression with significant difference $(t=1.34, d f=198, p=0.180)$.

\section{DISCUSSION}

The present study found out a significant difference among diabetic and normal adults in respect to aggression, verbal aggression, anger and hostility (Table II). Previous studies indicated an association of diabetes mellitus with aggressive and violent behaviors. ${ }^{21}$ Imbalance in glucose level makes the ground for expressing aggression and committing crimes. Instability of glucose level may also bring changes in moods of diabetic patients. These mood swings may also lead to certain behavioral and emotional changes such as: irritation and anxiety. Owing to these severe emotional and behavioral changes, diabetic patients of the present study might have exhibited more aggression (verbal aggression, anger and hostility) than comparative group. Previous studies also proved a significant association of anxiety with aggression, hostility and anger. ${ }^{22}$

It is empirically proved that low blood glucose level has significant association with aggression. ${ }^{23}$ Usually, the blood glucose level gets down when diabetic patients feel need to take food. As a result, diabetic patient usually become more angry and hostile towards others when they feel hungry. That reason also might be the one cause of exhibiting more aggression among patients with T2DM in comparison to normal adults.

Previous research reported that diabetic patients experience frustration and disappointment. ${ }^{14}$ It is already known that frustration is associated with anger that instigates aggression on receiving aggressive cues. ${ }^{24}$ So, it can be inferred that diabetic patients of the present study might have difficulty in tolerating frustrating situation. Consequently, they expressed more verbal aggression, anger and hostility than normal adults.

Diabetic patients persistently experience distress due to the diabetes related requirements including proper diet management and physical exercises. ${ }^{25}$ As a result, diabetic patients internally experience more emotional burden and worries. This diabetes related distress predicts psychological distress among patients with T2DM. ${ }^{26}$ In the current study, this psychological distress might have exhibited in the form of verbal aggression, anger and hostility towards others. Despite all these reasons, diabetic and normal adults equally expressed physical aggression towards external environment in response to their hidden aggression feelings and thoughts as depicted by the results.

\section{LIMITATIONS}

Some significant limitations were noted on the completion of present study. Only one form of diabetes mellitus (type 2) was studied as a risk factor of aggression. The question related to the role of type I in goading aggression was not addressed indicating a serious limitation of the study. Aggression may also be the result of both types of diabetes mellitus. The present study also failed to demonstrate the different influence of both types of diabetes on aggressive behavior of an individual. Hence, future researchers are recommended to dig out the role of both types

TABLE II:SUMMARY OF INDEPENDENT SAMPLES T-TEST SHOWING DIFFERENCE AMONG GROUPS ON THE VARIABLE OF AGGRESSION AND ITS COMPONENTS

\begin{tabular}{|c|c|c|c|c|c|c|c|}
\hline \multirow{3}{*}{ Variables } & \multicolumn{4}{|c|}{ Groups } & & & \\
\hline & \multicolumn{2}{|c|}{$\begin{array}{l}\text { Adults with Type } 2 \\
\text { Diabetes Mellitus } \\
(n=100)\end{array}$} & \multicolumn{2}{|c|}{$\begin{array}{l}\text { Normal Adults } \\
\qquad(n=100)\end{array}$} & \multicolumn{3}{|c|}{$\begin{array}{l}\text { INDEPENDENT } \\
\text { SAMPLES T-TEST }\end{array}$} \\
\hline & Mean & SD & Mean & SD & df & $\mathbf{t}$ & p-value \\
\hline Physical aggression & 23.61 & 6.88857 & 22.39 & 5.90650 & 198 & I.344 & 0.180 \\
\hline Verbal Aggression & 18.85 & 7.16948 & 15.93 & 7.29086 & 198 & 2.856 & 0.005 \\
\hline Anger & 22.61 & 5.32935 & 20.40 & 5.35224 & 198 & 2.926 & 0.004 \\
\hline Hostility & 23.41 & 6.33473 & 19.89 & 5.33692 & 198 & 4.298 & 0.000 \\
\hline Aggression & 87.78 & 17.25658 & 78.61 & 15.92082 & 198 & 3.906 & 0.000 \\
\hline
\end{tabular}


of diabetes mellitus in determining emotional and behavioral problems (i.e, aggression) among diabetic patients. Mediating role of gender, age and duration of disease can further assist in clarifying the role of diabetes in aggression. In this regard, random selection of the participants for future studies may also adequately justify the impact of diabetes on individual's psychological health.

\section{CONCLUSION}

T2DM is a potent risk factor of aggression in adults. Mostly, diabetic patients become verbally aggressive towards others. They also respond to external environment with intense anger and hostility. Therefore, diabetic patients need to learn the management of their aggressive thoughts and acts besides coping with their diabetes.

\section{IMPLICATIONS}

The present findings have implications for physical/mental health practitioners and diabetic patients. In clinical setting, practitioners must take into account the aggression as associated significant problem of T2DM like other problems of physical nature. Maintenance of glucose level in body using precautions and effective treatment procedures helps patients in overcoming their aggression as well. Patients with T2DM need to be counsel by health professionals how to overcome or manage their diabetes and aggressive feelings and acts in daily routine. In the light of present findings, normal adults can also be suggested to use precautions and adopt healthy lifestyle in order to prevent T2DM to be saved from psychological consequences as well such: as aggression.

\section{REFERENCES}

I. World Health Organization (WHO). Diabetes. [Accessed on: September II; 2019]. Available from URL: https://www.who.int/news-room/ fact-sheets/detail/diabetes.

2. International Diabetes Federation (IDF). Diabetes Atlas $7^{\text {th }}$ Edition. [Accessed on: September II; 2019]. Available from URL: https:// www.idf.org/sites/default/files/EN 6E_Atlas_Full_0.pdf.
3. World Health Organization (WHO). Eastern Mediterranean Region. Country and Regional Data on Diabetes. [Accessed on: September II; 2019) Available from URL: https://www.who.int/diabetes/facts /world_figures/en/index2.html

4. Qidwai W, Ashfaq T. Imminent epidemic of diabetes mellitus in Pakistan: Issues and challenges for health care providers. J Liaquat Uni Med Health Sci 20 I 0;9: I I 2-3.

5. Chen L, Magliano DJ, Zimmet PZ. The worldwide epidemiology of type 2 diabetes mellitus: Present and future perspective. Nat Rev Endocrinol 20I I;8:228-36. https:// doi.org/10.1038/nrendo.201 I.183

6. Koopmanschap M, Code-2 Advisory Board. Coping with type 2 diabetes: The patient's perspective. Diabetologia 2002;45: I8-22. https://doi.org/ I0. I007/s00 | 25-002-086 I-2

7. Polonsky WH, Fisher L, Earles J, Dudl RJ, Lees J, Muljan J, Jackson RA. Assessing psychological distress in diabetes: development of the diabetes distress scale. Diabetes Care 2005;28(3):626-31. https:// doi.org/10.2337/diacare.28.3.626

8. Samuel-Hodge CD, Headen SW, Skelly $A H$, Ingram AF, Keyserling TC, Jackson EJ, et al. Influences on day-to-day self-management of type 2 diabetes among African American women: Spirituality, the multi-caregiver role, and other social context factors. Diabetes Care 2000;23:928-33. https://doi.org/ 10.2337/diacare.23.7.928

9. Islam MR, Karim MR, Habib SH, Yesmin K. Diabetes distress among type 2 diabetes patients. Int J Med Biomed Res 20 I 3;2(2): I I3-24.

10. Alberti G. The Dawn (Diabetes Attitudes, Wishes and Needs) Study. Prac Diabetes Int 2002; I9(I): 22-4. https://doi.org/10.1002/ pdi. 305

I I. Jones JM, Lawson ML, Daneman D, Olmsted MP, Rodin G. Eating disorders in adolescents females with and without type I diabetes: Cross sectional study. $\mathrm{Br}$ Med J 2000;320: 1563-6. https://doi.org/
I0.1 |36/bmj.320.7249.1563

12. Rauf S, Rehman ZU, Abrar K. Frequency of psychiatric morbidity amongst patients with diabetes mellitus in a medical outpatient. Pak Armed Forces Med J 2005;55(I): I4-7.

13. Zaidi SMIH, Yaqoob N, Saleem R, Fatima A. Psychological distress and disease: Level of stress in victims of type 2 diabetes mellitus. J Postgrad Med Inst 20 I 7;3 I:25-8.

14. Ijaz S, Ajmal MA. Experiencing type 2 diabetes in Pakistan. Pak J Soc Clin Psychol 20I I;9:50-6.

15. Penckofer S, Ferrans CE, VelsorFriedrich B, Savoy S. The psychological impact of living with diabetes women' day-to-day experiences. Diabetes Educ 2007; 33:680-90. https://doi.org//0.1 I77/0 | 4572 I 70 7304079

16. Glassman WE, Hadad M. Approaches to Psychology. $5^{\text {th }}$ ed. McGraw Hill Education; 2009.

17. Alia-Klein N, Goldstein RZ, Kriplani A, Logan J, Tomasi D, Williams B, et al. Brain monoamine oxidase. An activity predicts trait aggression. J Neuro 2008a;28:5099-5I04. https://doi.org/10.1523/JNEUROS Cl.0925-08

18. Buss AH, Perry MP. The Aggression Questionnaire. J Pers Soc Psychol 1992;63:452-9.

19. Anderson CA, Bushman BJ. Human aggression. Annu Rev Psychol 2002;53:27-5I.

20. Shafiq F. Prevalence and Predictors of Aggression in Married Men and Women (M.Phil thesis). Deptt of Applied Psychol, GC Women Univ, FSD; 2017.

21. Dewall CN, Deckman T, Gailliot MT, Bushman BJ. Sweetened blood cools hot tempers: physiological self-control and aggression. Aggress Behav 20II;37(I):73-80. https://doi.org/10.1002/ab.20366

22. Chung JE, Song G, Kim K, Yee J, Kim $\mathrm{JH}$, Lee KE, Gwak HS. Association between anxiety and aggression in adolescents: a cross-sectional study. BMC Pediatr 2019;19:1।5. https://doi.org/I0. I |86/s I 2887- 


\section{$019-1479-6$}

23. Bushman BJ, DeWall CN, Pond RS, Hanus MD. Low glucose relates to greater aggression in married couples. Proc Natl Acad Sci USA (PNAS) 20I4; III(I7):6254-7. https://doi.org/10.1073/pnas. 14006 |91।
24. Myers DG. Exploring Social Psychology. $3^{\text {rd }}$ ed. New York: Worth Publishers; 1996.

25. Karlson B, Idsoe T, Dirdal I, Rokne $\mathrm{HB}$, Bru E. Effects of a group-based counseling program on diabetesrelated stress, coping, psychological well-being and metabolic control in adults with type I and type 2 diabetes.
Pat Educ Counsel 2004;53(3):299308. https://doi.org/10.1016/ j.pec.2003.10.008

26. Sadiq R, Batool A. Relationship of diabetes related distress with psychological distress in type 2 diabetic patients. J Postgrad Med Inst 20 I 7;3 I (4):405-9.

\section{AUTHOR'S CONTRIBUTION}

Following authors have made substantial contributions to the manuscript as under:

RF: Conception and study design, analysis and interpretation of data, drafting the manuscript, critical review, approval of final version to be published

FS: Conception and study design, acquisition of data, drafting the manuscript, approval of final version to be published

Al, MW, AK \& ME: Acquisition of data, drafting the manuscript, approval of final version to be published

Authors agree to be accountable for all aspects of the work in ensuring that questions related to the accuracy or integrity of any part of the work are appropriately investigated and resolved.

CONFLICT OF INTEREST
Authors declared no conflict of interest
GRANT SUPPORT AND FINANCIAL DISCLOSURE
Authors have declared no specific grant for this research from any
funding agency in the public, commercial or not-for-profit sectors

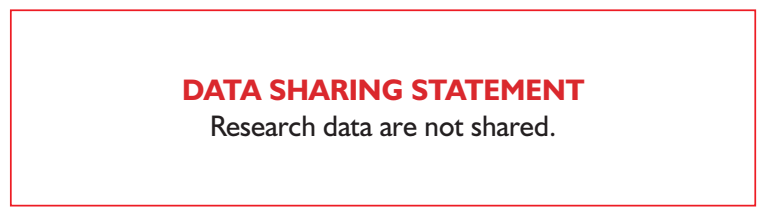

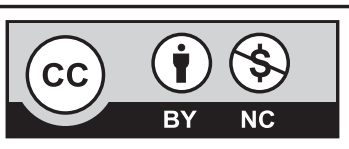

This is an Open Access article distributed under the terms of the Creative Commons Attribution-Non Commercial 2.0 Generic License.
KMUJ web address: www.kmuj.kmu.edu.pk

Email address: kmuj@kmu.edu.pk 